\title{
Socioeconomic factors associated with dysentery in children under-five years from developing countries
}

Ángela María Pinzón-Rondón ${ }^{1 *}$, Carol Jisseth Zarate-Ardila1, Laura Parra-Correa ${ }^{1}$, Alisson Zarate-Ardila², Paola Lozada-Calderón ${ }^{1}$ Leire Di Cecco ${ }^{1}$.

Affiliations:

$10{ }^{1}$ Escuela de Medicina y Ciencias de la Salud, Universidad del Rosario, Bogotá, Colombia.

112 Facultad de Medicina y Ciencias de la Salud, Universidad Militar Nueva Granada, Bogotá, 12 Colombia.

\section{${ }^{*}$ Corresponding author}

E-mail: angela.pinzon@urosario.edu.co (AMPR)

Abbreviations: ADD, Acute diarrheal disease; WHO, World Health Organization; DHS, Demographic and Health Survey; WB, World Bank; GDP Gross Domestic Product; United Nations, UN.

Keywords: Dysentery, Multilevel Analysis, risk factors, prevalence. 


\section{Abstract}

\section{Socioeconomic factors associated with dysentery in children under-five years from developing countries}

Objective: Dysentery represents $10 \%$ of all causes of acute diarrhea in the world and recognizing the implied proximal and distal social factors at different levels would impact on every related outcome. Our purpose is to identify mother, household and country characteristics that favor the presence of dysentery in children under 5 years old. Methods: We conducted a multilevel analysis of data from phase $V$ of the Demographic and Health Survey and the World Bank, which included 38,762 children from 33 countries. Results: Prevalence of dysentery was $14.74 \%$. GDP percapita was negative associated $(\mathrm{OR}=0.75 ; 95 \% \mathrm{Cl} 0.71-0.78)$ and Gini index was positive associated $(\mathrm{OR}=1.23 ; 95 \% \mathrm{Cl} 1.19-1.28)$. Additionally, child age (OR= 0.99; $95 \% \mathrm{Cl} 0.99-1.00)$, mother age (OR=1.01; $95 \% \mathrm{Cl} 1.00-1.01)$, employed mother $(\mathrm{OR}=1.11 ; 95 \% \mathrm{Cl} 1.02-1.20)$, and number of household members (OR= $1.02 ; 95 \% \mathrm{Cl} 1.01-1.03)$ have significant positive associations with the presence of dysentery, while complete immunization schedule (OR=0.88; $95 \% \mathrm{Cl} 0.81-0.96)$, duration of breastfeeding $(\mathrm{OR}=0.81 ; 95 \% \mathrm{Cl} 0.75-0.89)$, and type of residence $(\mathrm{OR}=$ $0.87 ; 95 \% \mathrm{Cl} 0.79-0.97)$ have significant negative associations with having the illness. Finally, each of the categories of wealth index showed a significant association with dysentery ( $p$-value $<0.001)$. Conclusions: Lower per capita GDP and higher Gini coefficient are associated with the development of dysentery, regardless of characteristics of children, their mother, and household. Future and 
61 present public health programs should address these issues in order to impact on

62 the occurrence of this illness.

63

64 Author summary

Dysentery represents $10 \%$ of all causes of acute diarrheal disease. Diarrhea

66 is the fifth cause of worldwide death in children under five years old. It is particularly

67 important to assess and prevent this condition because the early years of life are

68 critical since it is the period when the brain develops most rapidly and has a high

69 capacity for change. Complications associated with dysentery such as malnutrition

70 and convulsive episodes could have a negative effect in this aspect.

71 Our purpose is to identify the country proximal and distal socioeconomic

72 factors that favor the presence of dysentery in children under five years old from low

73 and middle-income developing countries in order to impact on the occurrence of this

74 illness and its related outcomes. Studying associated factors with developing

75 dysentery during an episode of acute diarrhea could be the base upon which we can

76 diminish mortality from this illness through national policies to impact on national,

77 community and household aspects.

78 


\section{Introduction}

85 Acute diarrheal disease (ADD) is defined as the presence of three or more 86 abnormally loose or watery stools in 24 hours. It is the second cause of death in 87 children under five years old [1,2], with a worldwide prevalence of about $8 \%$ [3]. This 88 illness is caused usually by the presence of microorganisms in contaminated food 89 or drinking water [4], most of the times by rotavirus, which accounts 527,000 deaths 90 annually. Eighty-two percent of these deaths occur in the poorest countries [5]. The

91 second leading cause of ADD is related to a bacterial infection, in which $E$. coli 92 enteropathogenic is the most important involved microorganism [6].

93 Dysentery is an intestinal inflammation that can lead to severe diarrhea with 94 mucus or blood in the stools. It is a particularly worrying presentation of ADD [1] 95 usually accompanied by fever, abdominal pain and impaired general conditions. 96 Hence, it is defined as the presence of macroscopic blood and mucus in the stools $97[1,4]$

98 According to the World Health Organization (WHO), dysentery represents $9910 \%$ of all causes of ADD and accounts for $15 \%$ of all deaths from this cause. It is 100 also the fifth cause of death worldwide in children under five years old [7]. In 101 developing countries, shigellosis is the most frequent cause of dysentery in children, 102 with $99 \%$ of all cases in comparison to developed countries whose main etiology is 103 seasonal virus [4,6,8]. Complications associated with dysentery goes from 104 dehydration, malnutrition, and cognitive impairment to severe outcomes as 105 convulsive episodes, uremic syndrome and death [8]. It is worth recognizing, that 106 children are at higher risk to acquire this mentioned infection, not only because they 
107 have more contact with soil, but also because their immune system is still immature

108 for establishing an appropriate response to any microorganism [2].

109 In a recent study, we evaluated the relationship between some characteristics

110 of developing countries and the occurrence of diarrheal disease. We concluded that

111 residents of nations with higher inequality and lower incomes have greater

112 probabilities of having diarrhea, especially when there is a lack of household wealth

113 and mother's education [9].

114 Other factors that showed strong positive association with diarrhea were

115 female sex of the child, younger age of the child, incomplete immunization status,

116 birth weight, lack of education of the mother and an unemployed mother [9].

117 Recognizing dysentery risk factors would reduce not only mortality rates in

118 children under five years old but also would impact in every outcome related to this

119 disease. The aim of this article is to identify mother, household and country

120 characteristics that favor the presence or absence of dysentery in children under five

121 years old by analyzing the Demographic and Health Survey (DHS) phase $V$ in 33

122 nations. 
130

\section{Methods}

This is a cross-sectional, transnational and multilevel study. We used level-1 data (child, mother and household characteristics) from the Demographic and Health Survey (DHS) phase-V [10] and level-2 data (country characteristics) from the World Bank (WB) country data [11].

The DHS phase-V collected data from 41 developing countries from 2004 to 2010. A nationally representative, probabilistic sample including rural and urban areas was collected from each participating country. Respondents were selected through a multistage, stratified sampling procedure of households. Between 5,000 and 30,000 households were surveyed per country. Data was gathered for the countries included in Attachment 1. We excluded Ukraine from the analysis because this country did not apply the child health module of the survey. Information from the remaining 40 countries was merged to create a single dataset, which included 395,485 households with children. The dataset was further limited to biological mothers answering the survey to assure comparability $(384,662)$, living children $(359,527)$, permanent household residents $(349,849)$ and cases with complete information in variable diarrhea $(348,706)$. Afterward, the database was limited to cases that reported diarrhea during the two weeks before the interview $(49,065)$ in order to know how many of them had dysentery. Then, the database was finally limited to cases with complete information in the variable dysentery $(38,762)$. Finally, we have information from 33 countries because Bangladesh, Benin, Congo, Democratic Republic of the Congo, Indonesia, Mali, and Niger did not have information about dysentery [10]. 
After careful analysis, we concluded that the WB country data was the best

154 source of level-2 data in this study because of its country comparability and

155 robustness when compared to data from other sources. These data included the

1562010 indicators: per capita gross domestic product (GDP), Gini-coefficient, and

157 health expenditure as a percentage of GDP.

Outcome Variable

Dysentery: the presence of bloody diarrhea (as defined by the respondent,

161 the child's mother). Dysentery was asked by DHS to the mothers whether there was

162 any blood in the stools of those children who had diarrhea at any time during the two

163 weeks preceding the interview $(0=$ no; $1=$ yes $)$.

166 We divided the variables according to the data source: level-1 variables

167 included the child, mother and household characteristics, and level-2 variables

168 included country data. At first, we considered three levels of analysis -child,

169 household, and country- but most households had only one child under the age of

170 five, so it was decided to include only one child per household, the youngest, and

171 conduct a two-level analysis.

Level-1 data, children: age of the child in months, sex, possession of the

174 health card, immunization defined as the completeness of WHO schedule, duration

175 of breath feeding in months, birthweight, twin pregnancy, cesarean section, bottle

176 feeding with a nipple. Even though it is not ideal to include a birthweight-missing 
177 indicator, taking into consideration that $46 \%$ of the children did not have this

178 information, imputation was ruled out.

Level -1 data, mother: age in years, education o educational attainment,

181 current employment, marital status, total children and partner age

Level -1 data, mother's pregnancy: planned pregnancy, antenatal visits.

Level -1 data, household: household members defined as the number of

187 floor material, years living at the house, sanitation score based upon water source and waste disposal and wealth index calculated by the DHS considering income, possessions, and quality of life [12].

192 Low income (1 = gross domestic product per capita (GDPpc) of US\$1,025 or less), 193 Lower middle income (1 = GDPpc between US\$1,026 and US\$4,035), Upper middle

194 income (1 = GDPpc between \$4,036 and \$12,475), and High income (1 = GDPpc of $195 \$ 12,476$ or more) [15]. Inequality based on the Gini coefficient ( $1=$ top $25 \%$ unequal 196 countries and $0=$ more equal countries) and health expenditure coded as a set of 197 dummy variables based on the percentage of GDP expended on health. Low health 198 expenditure ( $1=5 \%$ or less), Middle health expenditure $(1=$ between 5.1 and 10 $199 \%)$, High health expenditure $(1=$ more than $10 \%)$. We considered in the initial 200 models country homicide rates and total country population, but these variables were 
201 omitted in the final models because of their lack of association with dysentery and

202 their negative effects on the model's validity, measured using residual files and 203 reliability estimates.

205 Statistical Analysis

The analysis was conducted considering known factors associated with

207 dysentery and the country characteristics studied. Multilevel analyses were preferred

208 because the hierarchical nature of the data violated the principles of independence

209 and homogeneity required for a single-level analysis [13].

210 The statistical analysis was performed using SPSS 20.0 (IBM) and HLM 7

211 (Scientific Software International, Inc.), as follows: 1) we merged the individual

212 datasets of the 40 countries, 2) we filter out the database following the inclusion and

213 exclusion criteria explained above obtaining information from 33 countries, 3) we

214 calculated descriptive statistics for categorical (proportions) and numerical variables

215 (mean, standard deviation, minimum and maximum values), 4) we obtained bivariate

216 odds ratios using hierarchical linear modeling logistic regressions of dysentery in all

217 of the studied variables, and 5) we generated multivariable models for dysentery

218 using hierarchical linear modeling. Stepwise multilevel logistic regression equations

219 were estimated. Individual, family and household factors were included as possible

220 predictors of dysentery, and differences were deemed to be significant with P-value

221 less than 0.05. The large sample size allowed us to find small differences with narrow

$22295 \%$ confidence intervals. Finally, multilevel modeling was used to explore the

223 association of country characteristics with dysentery (between countries

224 associations) adjusting for individual, family and household predictors of the 
225 condition (within countries associations) [14,15]. Full maximum likelihood was used

226 to fit the models. Random effects were estimated only for indicators with variations

227 between groups that could be explained by the studied variables, allowing the

228 coefficients to vary across groups. Those level-1 indicators were centered on the

229 country mean to avoid the problem of co-linearity. All other variables, as well as the

230 neighborhood variables, were centered on the grand mean and we constrained their

231 variance. Level 2 country data variables were dichotomized and analyzed into $50 \%$

232 higher and $50 \%$ lower. The final model can be seen in Table 4. We have calculated

233 median odd ratios (MORs) and intra-class correlations (ICC) for the models, as well

234 as $80 \%$ interval odds ratios (IORs) for the country level variables $[16,17]$.

235 We tested bivariate interactions by multiplying duration of breastfeeding and

236 maternal education, duration of breastfeeding and maternal employment,

237 immunization and maternal education, and wealth index and immunization to

238 determine if an interaction was present.

239 Within countries, weights provided by the DHS for children under 5 years old

240 were employed in the analysis for the level-1 data. They were adjusted to the survey

241 design. Post-stratification was incorporated as a weight adjustment. The adjusted

242 weights were used in all of the analyses. For level-2 data, between countries,

243 weights were created and used in the analysis for each country accounting for their

244 population.

245 Regression analyses considering the DHS year of survey were performed to

246 assure that the results were not biased by the different time lapses the surveys took

247 place at each country. 
249 this study. The study was based on secondary sources without identifying

250 information about individual participants. It was given approval by the institutional

251 review board, Comité de Ética en Investigación, Universidad del Rosario.

\section{Results}

255 countries, who presented diarrhea during the last two weeks before the interview,

256 according to the mother's report. The descriptive features of the evaluated

257 population are shown in Table 1. They are separated from children who did and did

258 not present dysentery in their last episode of diarrhea.

\begin{tabular}{|c|c|c|}
\hline Variables & NO Dysentery & Dysentery \\
\hline \multicolumn{3}{|l|}{ Children } \\
\hline Dysentery \% (n) & $85.25(33,048)$ & $14.74(5,714)$ \\
\hline Age in months median (IQR) & $19(22)$ & $24(22)$ \\
\hline Female sex $\%(n)$ & $47.32(15,639)$ & $47.67(2,724)$ \\
\hline Possession of health card $\%(n)$ & $87.82(29,026)$ & $85.35(4,877)$ \\
\hline Complete immunization schedule $\%(n)$ & $63.72(21,060)$ & $55.98(3,199)$ \\
\hline Planned pregnancy $\%(n)$ & $57.17(18,895)$ & $53.02(3,030)$ \\
\hline \multicolumn{3}{|l|}{ Antenatal visits $\%(n)$} \\
\hline None & $9.47(3,131)$ & $11.06(632)$ \\
\hline $1-2$ & $10.02(3,312)$ & $9.53(545)$ \\
\hline $3-10$ & $59.77(19,753)$ & $56.09(3,205)$ \\
\hline More than 10 & $4.16(1,376)$ & $2.55(146)$ \\
\hline Missing information & $16.56(5,476)$ & $20.75(1,186)$ \\
\hline \multicolumn{3}{|l|}{ Birth weight $\%(n)$} \\
\hline Low & $6.25(2,066)$ & $5.19(297)$ \\
\hline Normal & $48.17(15,921)$ & $40.47(2,313)$ \\
\hline Not weighed or not remember & $45.057(15,061)$ & $54.32(3,104)$ \\
\hline Cesarean delivery $\%(n)$ & $11.08(3,665)$ & $8.76(501)$ \\
\hline Duration of breastfeeding (months) median (IQR) & $13(10)$ & $15(10)$ \\
\hline Still breastfeeding $\%(n)$ & $62.07(20,514)$ & $56.10(3,206)$ \\
\hline Drinking from a bottle with a nipple $\%(n)$ & $22.44(7,418)$ & $17.72(1,013)$ \\
\hline Twin pregnancy $\%(n)$ & $1.99(659)$ & $1.90(109)$ \\
\hline Mother & & \\
\hline
\end{tabular}


bioRxiv preprint doi: https://doi org/10.1101/664607; this version posted June 8,2019 . The copyright holder for this preprint (which was not

certified by peer review) is the author/funder, who has granted bioRxiv a license to display the preprint in perpetuity. It is made available under aCC-BY 4.0 International license.

\begin{tabular}{|c|c|c|c|}
\hline \multirow[t]{2}{*}{260} & Age (years) median (IQR) & $27(10)$ & $28(11)$ \\
\hline & Educational attainment $\%(n)$ & & \\
\hline \multirow{3}{*}{261} & No education & $24.23(8,010)$ & $30.36(1,735)$ \\
\hline & Elementary & $39.38(13,017)$ & $44.50(2,543)$ \\
\hline & High school & $30.24(9,995)$ & $21.92(1,253)$ \\
\hline \multirow[t]{2}{*}{262} & Superior & $6.12(2,025)$ & $3.18(182)$ \\
\hline & Mother's Employment \% (n) & $47.76(15,787)$ & $57.47(3,284)$ \\
\hline \multirow{2}{*}{263} & Marital status $\%(n)$ & & \\
\hline & Single & $4.27(1,669)$ & $4.48(256)$ \\
\hline \multirow{3}{*}{264} & Married & $88.34(29,195)$ & $87.73(5,013)$ \\
\hline & Divorced separated or widow & $7.38(2,440)$ & $7.78(445)$ \\
\hline & Total children ever born median (IQR) & $3(3)$ & $3(3)$ \\
\hline \multirow{2}{*}{265} & Partner age (years) $\%(n)$ & & \\
\hline & Under 20 & $0.58(193)$ & $0.36(21)$ \\
\hline \multirow{3}{*}{266} & Between 20 and 40 & $70.77(23,391)$ & $65.68(3,753)$ \\
\hline & Above 40 & $16.43(5,430)$ & $20.86(1,192)$ \\
\hline & Missing information & $12.20(4,034)$ & $13.09(748)$ \\
\hline \multirow[t]{2}{*}{267} & Household & & \\
\hline & Number of household members median (IQR) & $6(4)$ & $6(3)$ \\
\hline \multirow{3}{*}{268} & Male-headed households \% ( $n$ ) & $82.17(27,157)$ & $80.71(4,612)$ \\
\hline & Age of head of household median (IQR) & $36(18)$ & $37(17)$ \\
\hline & Who is the head of household $\%(n)$ & & \\
\hline \multirow[t]{2}{*}{269} & Mother & $9.61(3,179)$ & $11.37(650)$ \\
\hline & Husband & $64.64(21365)$ & $66.22(3,784)$ \\
\hline \multirow{3}{*}{270} & Other relative & $25.73(8,504)$ & $22.40(1,280)$ \\
\hline & Urban residence $\%(n)$ & $65.20(21,548)$ & $73.90(4,223)$ \\
\hline & Floor material \% (n) & & \\
\hline \multirow[t]{2}{*}{271} & Soil or sand & $44.65(14,758)$ & $56.72(3,241)$ \\
\hline & Wood & $11.51(3,804)$ & $11.95(683)$ \\
\hline \multirow[t]{2}{*}{272} & Finished floor & $43.83(14,486)$ & $31.32(1,790)$ \\
\hline & Years living at house $\%(n)$ & & \\
\hline \multirow{3}{*}{273} & Under one & $4.03(1,333)$ & $3.85(220)$ \\
\hline & Between one and five & $22.64(7,485)$ & $21.21(1,212)$ \\
\hline & More than five & $62.34(20,604)$ & $66.13(3,779)$ \\
\hline \multirow{2}{*}{274} & Missing information & $10.97(3,626)$ & $8.80(503)$ \\
\hline & Inadequate sanitation score $\%(n)$ & $16.70(5,520)$ & $23.27(1,330)$ \\
\hline \multirow{3}{*}{275} & Wealth index $\%(n)$ & & \\
\hline & Poorest & $27.78(9,182)$ & $37.45(2,140)$ \\
\hline & Poorer & $22.82(7,543)$ & $25.28(1,445)$ \\
\hline \multirow[t]{3}{*}{276} & Middle & $20.42(6,749)$ & $18.34(1,048)$ \\
\hline & Richer & $16.75(5,537)$ & $12.58(719)$ \\
\hline & Richest & $12.21(4.037)$ & $6.33(362)$ \\
\hline
\end{tabular}

278

279

280

281

282

283 
The prevalence of dysentery was $14.74 \%$. The median age of the children

285 who had dysentery was 24 months, and the median age among the children who did

286 not present it was 19 months. In addition, only $56 \%$ of the children who had dysentery

287 had their immunization schedule completed, in contrast with children who did not 288 present dysentery who accounted for 63\%, approximately.

Nearly half of the children who did not have dysentery had normal weight 290 (48\%). However, this percentage was lower among the group of children who did 291 present the illness (41\%). Moreover, this last group of children was breastfed a 292 median of 15 months, in comparison with the group of children who did not present 293 dysentery and was breastfed a median of 13 months.

294 Approximately, $24 \%$ of the mothers did not have any level of education in the 295 group of children who had present dysentery. Nevertheless, this value was higher in 296 the group of the mothers of children who did present dysentery (30\%). Additionally, 297 more than half of this last group of mothers was employed (57\%). Finally, the higher 298 the wealth index was, the lower its percentage became in both groups of children.

299 Furthermore, the prevalence of dysentery in each of the evaluated countries 300 is shown in Figure 1. The Republic of Liberia presented the highest prevalence of 301 dysentery in the whole group of countries, and Colombia had the highest one among 302 the evaluated Latin-American countries. 
Figure 1. Prevalence of dysentery in evaluated countries

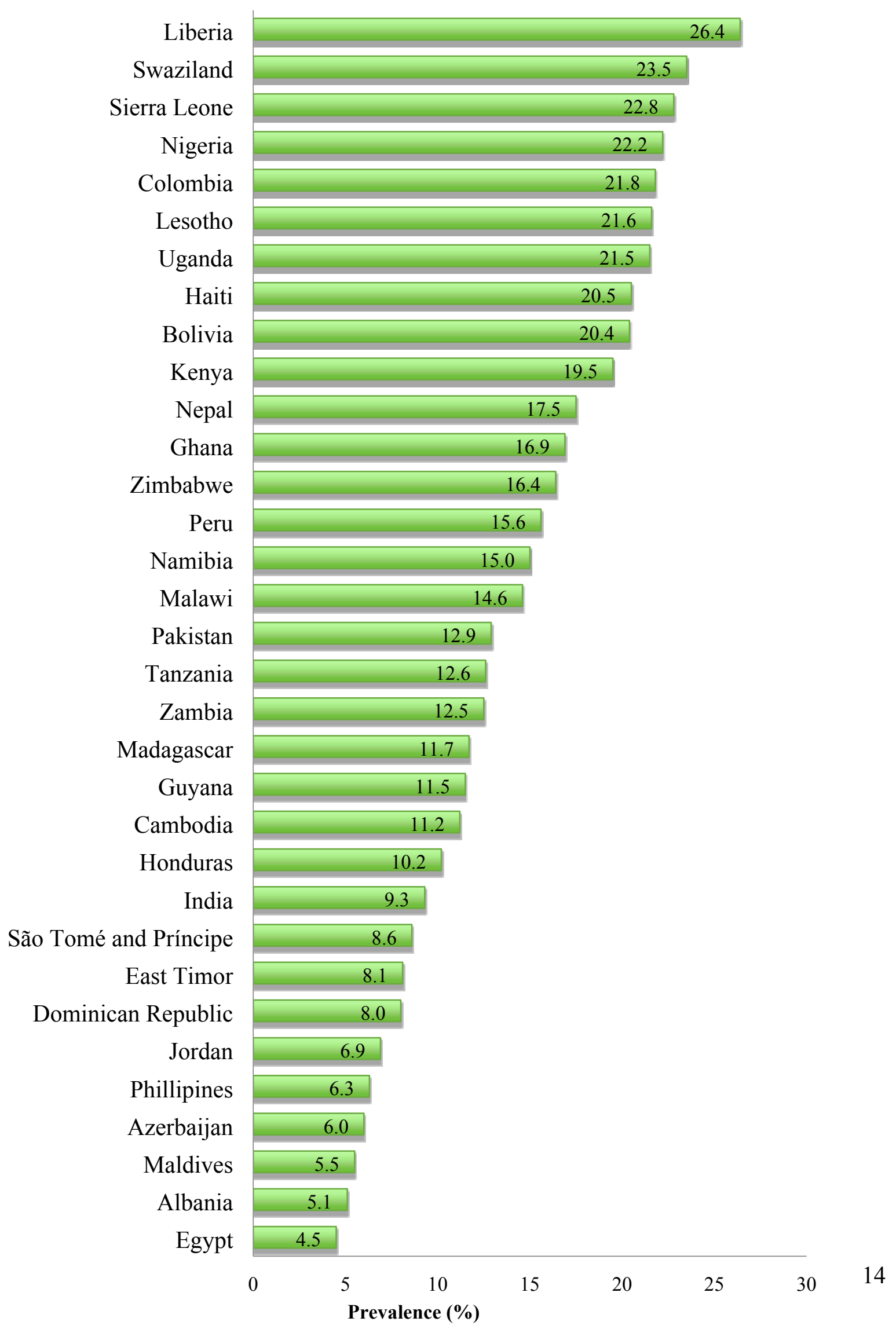


305 2. Approximately, $58 \%$ of children who had dysentery also had fever. Likewise, this

306 group of children received almost $55 \%$ and $27 \%$ of oral rehydration and antibiotic

307 therapy, respectively. However, they did receive lower amounts of liquids and solids

308 during illness (61\% and 38\%, respectively), than the group of children who did not

309 present dysentery (67\% and $43 \%$, respectively).

$310 \quad$ Table 2. Signs, symptoms and characteristics related to dysentery from children under five years from 33 countries, 2004-2010.

\begin{tabular}{|l|c|c|}
\hline \multicolumn{1}{|c|}{ Variables } & NO Dysentery & Dysentery \\
\hline Fever \% $(n)$ & $45.66(15,090)$ & $58.54(3,347)$ \\
\hline Heard or used oral rehydration salts \% $(n)$ & $83.85(27,712)$ & $83.40(4,766)$ \\
\hline Visited an appropriate place for medical treatment \% $(n)$ & $51.27(16,947)$ & $58.69(3,354)$ \\
\hline Received oral rehydration solutions \% $(n)$ & $47.34(15,645)$ & $54.91(3,138)$ \\
\hline Received antibiotic treatment \% $(n)$ & $20.99(6,937)$ & $26.96(1,541)$ \\
\hline Offered adequate amount of liquids during illness \% $(n)$ & $67.55(22,327)$ & $61.46(3,512)$ \\
\hline Offered adequate amount of solids during illness \% $(n)$ & $43.86(14,497)$ & $38.08(2,176)$ \\
\hline
\end{tabular}

316 each one of the others included variables.

\begin{tabular}{|l|c|c|}
\hline \multicolumn{1}{|c|}{ Table 3. Bivariate regressions of dysentery on independent variables } \\
\hline \multicolumn{1}{|c|}{ Variables } & OR & P- value \\
\hline Children & & \\
\hline Age (months) & 1.01 & 0.000 \\
\hline Female sex & 1.01 & 0.624 \\
\hline Possession of health card & 0.81 & 0.000 \\
\hline Complete immunization schedule & 0.72 & 0.000 \\
\hline Planned pregnancy & 0.85 & 0.000 \\
\hline None antenatal visit & 1.19 & 0.000 \\
\hline 1-2 antenatal visits & 0.95 & 0.259 \\
\hline 3-10 antenatal visits & 0.86 & 0.000 \\
\hline More than 10 antenatal visits & 0.60 & 0.000 \\
\hline Missing information about antenatal visits & 1.32 & 0.000 \\
\hline Low weight at birth & 0.82 & 0.002 \\
\hline Normal weight at birth & 0.73 & 0.000 \\
\hline Not weighted at birth or not remember & 1.42 & 0.000 \\
\hline Cesarean delivery & 0.77 & 0.000 \\
\hline Duration of breastfeeding (months) & 1.03 & 0.000 \\
\hline Still breastfeeding & 0.78 & 0.000 \\
\hline Drinking from a bottle with a nipple & 0.75 & 0.000 \\
\hline Twin pregnancy & 0.96 & 0.665 \\
\hline Mother & & \\
\hline Age (years) & 1.02 & 0.000 \\
\hline No education & 1.36 & 0.000 \\
\hline Elementary & 1.23 & 0.000 \\
\hline
\end{tabular}




\begin{tabular}{|l|c|c|}
\hline High school & 0.65 & 0.000 \\
\hline Superior & 0.50 & 0.000 \\
\hline Employed & 1.48 & 0.000 \\
\hline Single & 1.50 & 0.482 \\
\hline Married & 0.94 & 0.187 \\
\hline Divorced & 1.06 & 0.282 \\
\hline Total children ever born & 1.10 & 0.000 \\
\hline Partner under 20 years old & 0.63 & 0.041 \\
\hline Partner between 20 and 40 years old & 0.79 & 0.000 \\
\hline Partner above 40 years old & 1.34 & 0.000 \\
\hline Missing information about partner age & 1.08 & 0.061 \\
\hline Household & & \\
\hline Number of household members & 1.03 & 0.000 \\
\hline Female household head & 1.10 & 0.008 \\
\hline Age of head of household & 1.00 & 0.760 \\
\hline Mother household head & 1.21 & 0.000 \\
\hline Husband household head & 1.07 & 0.021 \\
\hline Other relative household head & 0.83 & 0.000 \\
\hline Rural residence & 0.66 & 0.000 \\
\hline Soil or sand & 1.62 & 0.000 \\
\hline Wood & 1.04 & 0.334 \\
\hline Finish floor & 0.59 & 0.000 \\
\hline Poorest & 1.56 & 0.000 \\
\hline Poorer & 1.15 & 0.000 \\
\hline Middle wealth index & 0.88 & 0.000 \\
\hline Richer & 0.72 & 0.000 \\
\hline Richest & 0.49 & 0.000 \\
\hline Adequate sanitation score & 0.66 & 0.000 \\
\hline IIIness & & \\
\hline Fever & 1.68 & 0.000 \\
\hline Heard or used oral rehydration salts & 0.97 & 0.400 \\
\hline Visited an appropriate place for medical treatment & 1.35 & 0.000 \\
\hline Received oral rehydration solutions during illness & 1.36 & 0.000 \\
\hline Received antibiotic treatment during illness & 1.39 & 0.000 \\
\hline Offered adequate amount of liquids during illness & 0.77 & 0.000 \\
\hline Offered adequate amount of solids during illness & 0.79 & 0.000 \\
\hline
\end{tabular}

Table 4. Multivariate multilevel logistic regressions for dysentery and country level characteristics.

\begin{tabular}{|l|c|c|c|}
\hline \multirow{2}{*}{ Variables } & \multicolumn{3}{|c|}{ Final model } \\
\cline { 2 - 4 } & OR & Cl & p-value \\
\hline Child sex & 1.03 & $(0.96-1.11)$ & 0.337 \\
\hline
\end{tabular}




\begin{tabular}{|c|c|c|c|}
\hline Child age & 0.99 & $(0.99-1.00)$ & $<0.001$ \\
\hline Vaccination & 0.88 & $(0.81-0.96)$ & 0.003 \\
\hline Normal weight at born & 0.95 & $(0.87-1.04)$ & 0.276 \\
\hline Duration of breastfeeding & 0.81 & $(0.75-0.89)$ & $<0.001$ \\
\hline Mother's age & 1.01 & $(1.00-1.01)$ & 0.002 \\
\hline \multicolumn{4}{|l|}{ Mother's education } \\
\hline No education & 1.25 & $(1.84-1.60)$ & 0.049 \\
\hline $\begin{array}{l}\text { Elementary level } \\
\text { education }\end{array}$ & 1.24 & $(0.98-1.57)$ & 0.065 \\
\hline $\begin{array}{l}\text { High school level } \\
\text { education }\end{array}$ & 1.03 & $(0.82-1.29)$ & 0.798 \\
\hline Superior level education & \multicolumn{3}{|c|}{ Comparison category } \\
\hline Employed mother & 1.11 & $(1.02-1.20)$ & 0.009 \\
\hline Married & 1.07 & $(0.95-1.20)$ & 0.242 \\
\hline $\begin{array}{l}\text { Number household } \\
\text { members }\end{array}$ & 1.02 & $(1.01-1.03)$ & $<0.001$ \\
\hline Type of residence urban & 0.87 & $(0.79-0.97)$ & 0.015 \\
\hline \multicolumn{4}{|l|}{ Household wealth } \\
\hline Poorest & 2.07 & $(1.72-2.49)$ & $<0.001$ \\
\hline Poorer & 1.78 & $(1.49-2.13)$ & $<0.001$ \\
\hline Middle & 1.49 & $(1.25-1.78)$ & $<0.001$ \\
\hline Richer & 1.38 & $(1.16-1.65)$ & $<0.001$ \\
\hline Richest & \multicolumn{3}{|c|}{ Comparison category } \\
\hline INTERCEPT & 0.14 & $(0.12-0.16)$ & $<0.001$ \\
\hline GDP per capita & 0.75 & $(0.71-0.78)$ & 0.003 \\
\hline Gini index & 1.23 & $(1.19-1.28)$ & $<0.001$ \\
\hline Health expenditure & 0.85 & $(0.80-0.89)$ & $<0.001$ \\
\hline \multirow{2}{*}{$\frac{\text { Random effects }}{\text { Intercept }}$} & $\begin{array}{l}\text { Standard } \\
\text { deviation }\end{array}$ & $\begin{array}{c}\text { Variance } \\
\text { component }\end{array}$ & $p$-value \\
\hline & 0.34 & 0.12 & $<0.001$ \\
\hline$\frac{\text { Reliability }}{\text { Intercept }}$ & \\
\hline
\end{tabular}

At the same time, this last model showed that child age, mother age,

325 employed mother, and the number of household members have significant positive

326 associations with having dysentery ( $p$-value less than 0.05). On the other hand,

327 complete immunization schedule, duration of breastfeeding, and the type of

328 residence have significant negative associations with having the illness ( $p$-value less

329 than 0.05).

Simultaneously, each one of the categories of wealth index showed a

331 significant association with dysentery (p-value less than 0.001). And it is possible to

332 appreciate that the richer a person is, the lower its odds ratios becomes 


\section{Discussion}

In this study, $14.7 \%$, of the 38,762 children under-five years who suffered from

336 diarrhea, had dysentery. This is consistent with the following data found. Diarrheal

337 diseases remain among the most common causes of mortality and morbidity in 338 children, particularly in low and middle-income countries. In 2013, of the 6.3 million

339 children worldwide who died before their fifth birthday about $7.94 \%$ died from 340 diarrhea (18). In a study in North Ethiopia with 241 participants, the overall 341 prevalence was $13.3 \%(19)$.

342 Similar to previous studies, we observed a positive correlation between 343 dysentery and mother's age, no education of the mother, employed mother, the 344 number of household members and poverty [21- 23], as well as a negative 345 correlation between dysentery and child age, vaccination, duration of breastfeeding 346 and urban residence [24,25].

347 It is worth mentioning that the household wealth showed a gradient of 348 association with dysentery that changed depending on the wealth category. This 349 confirms what was found by Chompook et al. in Thailand, [26] the poorer you are, 350 the more likely to get dysentery.

351 The country characteristics studied showed association with dysentery. A 352 negative correlation of GDP per capita and child dysentery was observed, which 353 means that the lack of economic production is associated with the health of children 354 at the country level. This finding is consistent with other epidemiological studies, 355 which present how the lack of economic resources at the country level is associated 
356 with the decrease and absence of opportunities and in turn with impaired health of

357 the population $[27,28]$.

358 The Gini index showed a positive correlation with dysentery. The degree of

359 inequality in the distribution of income is related to the health of children at the

360 country level. Inequalities create the sense of unfairness and feelings of injustice

361 and discrimination in the disadvantaged group, due to the difference in the

362 opportunities offered [29]. These feelings have the potential to undermine the

363 wellbeing of children and their families.

364 Health expenditure also showed a positive correlation to dysentery. It is likely

365 that when a country invests their money in health, it is giving its children the potential

366 to be healthier [30].

\section{Limitations}

Even though DHS has significant and well-known advantages related to

370 quality, comparability, and representativeness of the information, our study presents

371 some significant limitations.

$372 \quad$ First, due to its cross-sectional nature, it is not possible to establish any causal

373 relationship among studied variables. Second, as data was collected exclusively

374 from mothers, who are supposed to be the best relators about their child' s history,

375 related bias are likely to be found. Third, while DHS questionnaires are not executed

376 simultaneously in every country and social conditions tend to change over time,

377 some differences could be expected. However, our results did not change after

378 controlling for year of survey. Fourth, the variable definitions are limited by the 
379 established methodology of the DHS team. Finally, the resulting large sample size

380 contributes to an over-power analysis that could detect minimal effect sizes, and

381 these could mean slight biases in the sampling process.

\section{Conclusion}

This study explored, by using a multilevel analysis, the association between

384 per capita GDP, income inequalities (Gini coefficient), health expenditure and

385 dysentery, in a multinational population adjusted by individual, maternal and

386 household characteristics. We found that some factors like older age of the child and

387 their mother, an unemployed mother, lower number of household members, higher

388 wealth index, and higher Gini index are protective factors against dysentery; while,

389 lower GDP per-capita, incomplete immunization schedule, lower duration of

390 breastfeeding and rural residence are risk factors against the same illness.

Additionally, as in a previous study, health expenditure does not appear to

393 take part in developing dysentery. However, per capita GDP and Gini coefficient

394 keep showing an important involvement with progressing from acute diarrhea to

395 dysentery. Due to this, and in order to diminish the consequences of this morbid

396 presentation of acute diarrhea, countries weigh up ways of improving their per capita

397 GDP and diminishing inequalities. Studying associated factors with developing

398 dysentery during an episode of acute diarrhea could be the base upon which we can

399 diminish mortality from this illness.

\section{$401 \quad$ References}


402 1. World Health Organization. Diarrhoeal disease. 2017 May 2 [Cited 10 May 403 2018]. In: WHO Fact Sheets [Internet]. Available from: http://www.who.int/news$404 \mathrm{room} /$ fact-sheets/detail/diarrhoeal-disease.

2. Endo A, Salminen S, Prtty A, Kalliomki M, Isolauri E. Long-term monitoring 408 of the human intestinal microbiota from the 2 nd week to 13 years of age. Anaerobe. 409 2014;28:149-56

3. Unicef. Estimates of child cause of death, Diarrhoea 2018. June 2018 [Cited 20 July 2018]. In: Unicef Data. Available from: https://data.unicef.org/topic/childhealth/diarrhoeal-disease/.

4. Behrman R, Jenson HB, Kliegman R. Nelson. Tratado de Pediatría. Madrid

9. Pinzon-Rondon AM, Zarate-Ardila C, Hoyos-Martinez A, Ruiz-Sternberg AM,

7. World Health Organization. Global Burden of Disease. 2004. [Cited 10 May 2018]. In: WHO Fact Sheets [Internet]. Available from:http://www.who.int/healthinfo/global burden disease/GBD report 2004updat e part2.pdf.

5. Parashar UD, Burton A, Lanata C, Boschi-Pinto C, Shibuya K, Steele D, et al. Global Mortality Associated with Rotavirus Disease among Children in 2004. Journal of Infectious Diseases. 2009;200(S1) S9-S15

6. Gomez-Duarte OG. [Acute diarrheal disease caused by enteropathogenic Escherichia coli in Colombia]. Revista Chilena de Infectología. 2014;31(5): 577-86

8. Kotloff KL, Platts-Mills JA, Nasrin D, Roose A, Blackwelder WC, Levine MM. Global burden of diarrheal diseases among children in developing countries: Incidence, etiology, and insights from new molecular diagnostic techniques. Vaccine. 2017;35(49, Part A):6783-9

Velez-van-Meerbeke A. Country characteristics and acute diarrhea in children from developing nations: a multilevel study. BMC Public Health. 2015;15(1):811

10. MD. R. The DHS program. The Demographic health survey program. 2014.

MDR? master device record 
11. The World Bank. The World Bank Data Washington DC. 2014. [Cited 9 May 2018]. In: World Bank Open Data[Internet]. Available from: http://data.worldbank.org/

12. Hueb J, Bartram J, Helmer R. Global Water Supply and Sanitation Assessment 2000 Report. Unites States of America: World Health Organization; 2000

13. Sellström E, Bremberg S. Review Article: The significance of neighbourhood context to child and adolescent health and well-being: A systematic review of

14. Guang G, Hongxin Z. Multilevel Modeling For Binary Data. Annual Review of Sociology. 2000;26:441-62

15. McCoach DB. Hierarchical linear modeling. The reviewer's guide to quantitative methods in the social sciences. 2010:123-40.

16. Merlo J, Basile C, Ohlsson H, Beekman A, Johnell K, Per H, et al. A brief conceptual tutorial of multilevel analysis in social epidemiology: using measures of clustering in multilevel logistic regression to investigate contextual phenomena.

17. Kaufman JS. RE: "Appropriate Assessment Of Neighborhood Effects On Individual Health: Integrating Random And Fixed Effects In Multilevel Logistic Regression". American Journal of Epidemiology. 2005;162(6):602-3.

18. Thiam S, Diène AN, Fuhrimann S, Winkler MS, Sy I, Ndione JA, et al.

19. Gebrekidan Kahsay A, Teklemariam Z. Prevalence of Shigella among diarrheic children under-5 years of age attending at Mekelle health center, north Ethiopia. BMC Research Notes. 2015;8:788 
21. Ahmed A, Edward A, Burnham G. Health indicators for mothers and children in rural Herat Province, Afghanistan. Prehospital and Disaster Medicine. $2004 ; 19(3): 221-5$

22. Wang F, Pan J, Zhang S, Zhang H, Wang W, Tao F, et al. [Impact factors analysis on child neglect of children aged 3-6 year-old in rural areas of China]. Zhonghua Yu Fang Yi Xue Za Zhi [Chinese Journal of Preventive Medicine]. 2015;49(10):866-72.

23. Chang M, Groseclose SL, Zaidi AA, Braden CR. An ecological analysis of sociodemographic factors associated with the incidence of salmonellosis, shigellosis, and E. coli O157:H7 infections in US counties. Epidemiology and Infection. 2009;137(6):810-20

24. Bhutta ZA, Salam RA. Global Nutrition Epidemiology and Trends. Annals of

26. Chompook P, Todd J, Wheeler JG, von Seidlein L, Clemens J, Chaicumpa W. Risk factors for shigellosis in Thailand. International Journal of Infectious Diseases. 2006;10:425-33.

27. Ma Y, Zhang T, Yin F, Liu L, Lv Q. Spatio-Temporal Pattern and SocioEconomic Factors of Bacillary Dysentery at County Level in Sichuan Province, China. Scientific Reports. 2015;5:15264.

28. Nie C, Li H, Yang L, Zhong G, Zhang L. Socio-economic factors of bacillary dysentery based on spatial correlation analysis in Guangxi Province, China. PLoS ONE. 2014;9(7):e102020

29. Kawachi I, Subramanian SV. Neighbourhood influences on health. Journal of Epidemiology and Community Health. 2007;61(1):3-4. 
541 30. Musich S, Wang S, Hawkins K, Klemes A. The Impact of Personalized

542 Preventive Care on Health Care Quality, Utilization, and Expenditures. Population

543 Health Management. 2016;19(6): 389-397.

547 Supporting Information

548 S1 Fig. Prevalence of dysentery in evaluated countries.

549 S1 Table. Descriptive statistics from children under five years from 33

550 countries, 2004-2010 who reported diarrhea. Proportions for categorical

551 variables and median/interquartile range for numerical variables.

552 S2 Table. Signs, symptoms and characteristics related to dysentery from

553 children under five years from 33 countries, 2004-2010.

554 S3 Table. Bivariate regressions of dysentery on independent variables

555 S4 Table. Multivariate multilevel logistic regressions for dysentery and

556 country level characteristics.

559 Attachment \# 1

\begin{tabular}{|l|l|l|l|}
\hline Country & Year & Country & Year \\
\hline Albania & $2008-2009$ & Malawi & 2010 \\
\hline Azerbaijan & 2006 & Maldives & 2009 \\
\hline Bangladesh & 2007 & Mali & 2006 \\
\hline Benin & 2006 & Namibia & $2006-2007$ \\
\hline Bolivia & 2008 & Nepal & 2006 \\
\hline Cambodia & 2010 & Niger & 2006 \\
\hline
\end{tabular}


bioRxiv preprint doi: https://doi.org/10.1101/664607; this version posted June 8,2019 . The copyright holder for this preprint (which was not certified by peer review) is the author/funder, who has granted bioRxiv a license to display the preprint in perpetuity. It is made available under aCC-BY 4.0 International license.

\begin{tabular}{|l|l|l|l|}
\hline Colombia & 2010 & Nigeria & 2008 \\
\hline Congo & 2005 & Pakistan & $2006-2007$ \\
\hline Egypt & $2005-2006$ & Peru & $2004-2008$ \\
\hline Philippines & 2008 & Democratic Republic of Congo & 2007 \\
\hline Ghana & 2008 & Dominican Republic & 2007 \\
\hline Guyana & 2009 & & $2008-2009$ \\
\hline Haiti & $2005-2006$ & São Tomé é Príncipe & 2008 \\
\hline Honduras & $2005-2006$ & Swaziland & $2006-2007$ \\
\hline India & $2005-2006$ & Tanzania & 2010 \\
\hline Indonesia & 2007 & East Timor & $2009-2010$ \\
\hline Jordan & 2007 & Ukraine & 2006 \\
\hline Kenya & $2008-2009$ & Uganda & \\
\hline Lesotho & 2009 & Zambia & \\
\hline Liberia & 2007 & & 2006 \\
\hline
\end{tabular}

